THE topical glucocorticoids (GCs) represent the treatment of choice for many types of inflammatory dermatoses. Despite the extensive use of this class of drugs as first line therapy the mechanism of their action is uncertain. It is clear that the multiplicity of actions of the topical GCs is an important facet of their scope in the treatment of dermal disorders. The aim of this update is to review past and current theories regarding how these agents might work. Current understanding of the molecular mechanis $m$ of GC action has advanced sign ificantly over the past decade with the realisation that multiple system $s$ are responsible for transduction of GC effects at a molecular level. The two primary modes of action are via interaction directly with DNA or indirectly through modulation of specific transcription factors: the endpoint in both cases being modulation of specific protein synthesis. Both of these mechanisms will be discussed. In particular this review will concentrate on the possibility that a GC-inducible protein, termed lipocortin 1, may have a significant role to play in the anti-inflammatory actions of these drugs. Additionally it has become apparent that several inflam matory enzymes induced in inflam mation are sites of inhibitory action of the GCs, and the possibility that this occurs in the skin will be discussed paying particular attention to the inducible phospholipase $A_{2}$, nitric oxide synthase and cyclooxygenase systems.

Key words: hipocortin 1, annexin 1, dexamethasone, inflammation, nitric oxide synthase, cyclooxygenase, phospholipase $\mathrm{A}_{2}$

\section{Topical glucocorticoids and the skin-mechanisms of action: an update}

\section{A. Ahluwalia}

Centre for Clinical Pharmacology, University College London, The Cruciform Project, The Rayne Institute, 5 University Street, London WC1E 6JJ, UK

Tel: $+44(0) 1712096614$

Fax: +44(0)1718132846

Email:a.ahluwalia@ucl.ac.uk

\section{Introduction}

Topical glucocorticoid (GC) treatment of inflammatory disease was first recognized as a viable mode of therapy by the ophthalmologists. These specialists were quick to realize the potential of the GCs in inflammatory ocular conditions following Hench's description in 1949 of his, Noble Prize winning, studies demonstrating the anti-inflammatory effects of steroid treatment in rheumatoid arthritis. ${ }^{1}$ The dermatologists followed suit confirming the efficacy of these agents in skin disease. These rather humble beginnings initiated the ensuing revolutionary changes in the treatment of inflammatory skin conditions commencing with the first, albeit unsuccessful, trials with topical cortisone in $1950^{2}$ and $1951 .^{3}$ However soon after, in 1952, Sulzberger and Witten published the first well-controlled trial demonstrating the clearcut benefits of topical hydrocortisone in patients with inflammatory dermatological conditions. ${ }^{4}$ The 1960 s were the golden era for the GCs with the introduction of the first synthetic congeners (e.g. prednisolone) into the clinic, followed soon after by the fluorinated derivatives (such as dexamethasone) possessing much increased potency. The unmatched efficacy of these agents when treating skin disease has in part resulted in the neglect afforded to understanding the exact mechanisms of action of the topical GCs. The existence of a facile assay system for estimation of potency, termed the vasoconstrictor assay (described later), aided and abetted this situation. More recently, however, understanding of the mechanisms of steroid action, in systems other than the skin, has advanced significantly and several groups are now pursuing this newly gained knowledge with respect to the skin. This article reviews the past and present theories of the mechanism of action of the glucocorticoids with specific reference to their use in the treatment of skin disease.

\section{Mechanism of Action}

The GCs have a multiplicity of actions; anti-inflammatory, immunomodulatory, vasoconstrictor, gluconeogenic, anti-mitotic to name a few (see Table 1). It is believed that several of these actions contribute to the 
Table 1. Mechanisms of anti-inflammatory action of the topical glucocorticoids

\begin{tabular}{|c|c|}
\hline Action & Effect \\
\hline $\begin{array}{l}\text { Inhibition of } \\
\text { phospholipase } A_{2} \text { activity }\end{array}$ & $\begin{array}{l}\text { Decreased production of } \\
\text { lipid mediators } \\
\text { (prostaglandins, } \\
\text { leukotrienes, platelet- } \\
\text { activating factor) }\end{array}$ \\
\hline $\begin{array}{l}\text { Inhibition of } \\
\text { cyclooygena se induction }\end{array}$ & $\begin{array}{l}\text { Decreased prostaglandin } \\
\text { production }\end{array}$ \\
\hline $\begin{array}{l}\text { Inhibition of nitric oxide } \\
\text { synthase induction }\end{array}$ & $\begin{array}{l}\text { Decreased nitric oxide } \\
\text { production }\end{array}$ \\
\hline $\begin{array}{l}\text { Inhibition of cytokine } \\
\text { production }\end{array}$ & $\begin{array}{l}\text { Suppression of cell- } \\
\text { mediated inflammation }\end{array}$ \\
\hline $\begin{array}{l}\text { Inhibition of mast cell } \\
\text { activity and reduction of } \\
\text { mast cell number }\end{array}$ & $\begin{array}{l}\text { Decreased levels of mast } \\
\text { cell inflammatory } \\
\text { mediators (histamine, } \\
\text { 5-HT) }\end{array}$ \\
\hline Vasoconstriction & $\begin{array}{l}\text { Decreased local blood } \\
\text { flow }\end{array}$ \\
\hline
\end{tabular}

therapeutic efficacy of these drugs in the treatment of skin disease. Indeed it is often this multi-pronged attack that endows the GCs with the considerably greater therapeutic potency above other modes of treatment. On the downside however it is this plethora of disparate effects that may preclude their use, since to date it has not been possible to separate the required actions of the GCs from those that cause significant unwanted side-effects. Due to the diversity of conditions that the GCs may be used to treat it is important to appreciate that any particular action of a GC may be beneficial in the treatment of one disease yet responsible for a confounding side effect in another. For instance, the anti-mitotic nature of GCs is the property upon which their use in psoriasis is based, ${ }^{5}$ yet in the treatment of other inflammatory dermatoses results in skin atrophy and may often be the reason for cessation of topical GC treatment.

Topical GCs are prescribed for the treatment of many inflammatory conditions and today represent the drug type of choice for the treatment of most dermal inflammatory disease (Table 2). This is not to say that the topical GCs are a panacea for all skin disease, but perhaps may be regarded as the most effective single class of drugs providing such broad spectrum therapeutic benefit. The anti-inflammatory action of the topical GCs has variously been attributed to several different mechanisms, and it is now clear that it is a combination of the different properties of the GCs that act in concert to provide the therapeutic advantages of this class of drugs in the treatment of inflammatory skin disease. Additionally both the antimitotic and vasoconstrictor nature of the GCs are properties which, most likely, contribute to resolution of certain inflammatory skin disease. The anti-
Table 2. Inflammatory dermal diseases treated with topical glucocorticoids

\begin{tabular}{ll} 
Level of treatment & Disease \\
\hline Treatment of choice & Eczema \\
& Contact dermatitis \\
& Atopic dermatitis \\
& Lichen planus \\
& Lichen simplex chronicus \\
& Chronic dermatitis \\
& Neurodermatitis \\
& Insect and arthropod bites \\
& Burns and sunburns \\
& Keloids \\
& Psoriasis \\
Useful alternative or & Seborrhoeic dermatitis \\
adjunctive therapy & Chronic lupus \\
& erythematosus \\
& Alopecia areata \\
Isolated examples of & Acne \\
successful treatment & Bullous pemphigoid \\
& Cutaneous mastocytosis \\
\hline
\end{tabular}

mitotic effect is believed to confer the beneficial effects of topical GCs in the treatment of psoriasis, a disease characterized by a high cell turnover rate (for review see Van De Kerkhof and Van $\operatorname{Erp}^{6}$ ). The vascular effect i.e. vasoconstriction, also termed 'blanching' when applied to the skin surface, has been suggested to contribute to the anti-inflammatory effects of these drugs by virtue of the decreased blood flow to the inflamed site, however the mechanism for this effect is still unclear (for review see Walter and Williams ${ }^{7}$ ). Additionally it is this blanching response which forms the basis of the standard assay for the assessment of the potency of topical GCs. ${ }^{8,9}$ The immunosuppressive nature of these agents also confer benefit in treatment of dermal diseases and indeed experimentally it is clear that steroids block delayed hypersensitivity responses in the skin.

\section{Molecular mechanism of action}

\section{Topical GCs interact with GC receptor}

The specific biological actions of the topical steroids are brought about by interaction with the GC receptor. In the 1960 s and 1970 s several studies provided circumstantial evidence supporting the concept of steroid binding sites in skin by demonstration, for example, of $\left[{ }^{14} \mathrm{C}\right]$-cortisol retention in the stratum corneum ${ }^{10}$ and identification of soluble proteins with high affinity for certain GCs in rat skin homogenates. ${ }^{11}$ It was in 1971 that definitive evidence for the existence of these receptors in mouse skin was obtained, ${ }^{12}$ followed by confirmation of these receptors in humans, firstly in cultured human keratinocytes and langerhan cells and then human epidermis. ${ }^{13-15}$ 
The subcellular localization of the GC receptor is a matter of debate. Early immunocytochemical studies concluded that the GR in the unoccupied state remains primarily in the cytoplasm and it is only upon occupation with a GC, to form a GC-receptor complex (GC-R), that it translocates to the nucleus. ${ }^{16,17}$ This pattern of activity is quite different from all of the other members of the steroid receptor family i.e. oestrogen, progesterone and androgen receptors, however more recently it has been demonstrated that the mineralocorticoid receptor functions in a similar manner. ${ }^{18}$ In contrast some studies suggest that the receptor is solely nuclear, ${ }^{1,20}$ and the authors in these cases attribute this apparent difference in localization to immunocytochemical procedure. Recent studies agree with cytoplasmic alocalization of the receptor but in association with the microtubule network (for review see Akner et al. ${ }^{21}$ ). This association with cytoskeletal filaments may explain how the GC on binding to the receptor is transported to the nucleus. In contrast some studies show no association of the cytosolic receptor with microtubular filaments. ${ }^{22}$ The prevailing belief at the present time is however that the receptor is cytoplasmic and translocates to the nucleus once bound to GC.

Specific GC functionality is conferred by binding to the receptor and this has been demonstrated for many of those effects which are anti-inflammatory. For example both oestradiol and testosterone, full GC receptor antagonists, were shown to block the blanching activity of clobetasol-propionate in the human forearm. ${ }^{23}$ This was supported by later studies with the GC receptor antagonist, RU38486, where prior systemic treatment of human volunteers with the antagonist completely blocked the blanching response to topically applied clobetasol-propionate. ${ }^{24}$

\section{GC-R complex activity}

(i) Interactions with DNA. Classically the mechanism of action of the GCs was thought to be brought about by changes in gene expression. It is now clear, however, that there are two modes of action of the activated GC receptor; those via interactions directly with DNA and those through protein-protein interactions with transcription factors. The end-point in each case is the same i.e. the alteration of the synthesis of key proteins.

Once the GC crosses the cell membrane it is thought that it binds with cytoplasmic receptor (R) to form a GC-R complex. The unliganded receptor is a heterotetrameric complex comprised of heat-shock proteins (hsp), hsp70 and hsp90, and chaperone immunophilins (for reviews see Pralt ${ }^{25}$ and Smith and $\left.\mathrm{Toft}^{26}\right)$. The sequelae following GC-R complex binding with DNA have been characterized and it is thought that interaction with genomic DNA accounts for most GC-induced effects (for a recent review on GC-receptor binding mechanisms see Brann et al. ${ }^{27}$ ).
Briefly GC-receptor binding causes a conformational change of the receptor with consequent shedding of the DNA-binding domain capping protein, hsp $90 .^{28,29}$ Exposure of the DNA-binding site allows binding of the GC-R complex to the GC response element (GRE). This interaction stimulates alterations in transcription, either positively or negatively, and thereby translation of proteins. One particular anti-inflammatory protein that is induced in this way is lipocortin 1 (LC1), also known as annexin 1, a member of the annexin family. ${ }^{30}$ This protein has attracted considerable interest as an important mediator of the anti-inflammatory action of the GCs and this review will highlight the activity of this protein in particular.

(ii) Protein-protein interactions. Whilst a considerable component of GC-R complex activity has been attributed to interaction with GREs, gene repression may also be modulated indirectly by protein-protein interactions between the activated GR and other transcription factors the reby altering protein synthesis without binding to GREs. Of particular interest is the inhibitory effect of GCs on two essential regulatory transcription factors for several genes involved in the inflammatory process; AP-1 and NFkB. These factors regulate the expression of inflammatory cytokines and adhesion molecules and indeed inhibition of the activity of these transcription factors has profound effects on inflammatory and immune responses. ${ }^{31,32}$

Whilst it seems clear that the GC-R complex binds directly with AP-1, thereby blocking AP-1-dependent gene expression, ${ }^{33}$ the mode of interference with $\mathrm{NF \kappa B}$ is less clear. NFKB exists constitutively in the cytosol as a heterodimer (p50 and p65 subunits), and is maintained in an inactive form by association with IкB. ${ }^{34}$ Exposure to inflammatory stimuli results in rapid degradation of $\mathrm{I} \kappa \mathrm{B}$ allowing free $\mathrm{NF \kappa B}$ to translocate to the nucleus where it binds with promoter elements on certain inflammatory genes. Originally it was thought that the GC-R complex binds directly with NFKB, however in 1995 it was shown, in a cultured monocytic T-cell hybridoma cell line, that the activated receptor may decrease free NFKB levels

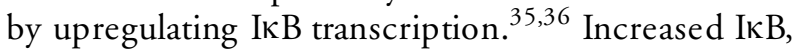
in turn, would sequester NFKB thereby depressing the levels of free NFKB available for binding to target genes. This theory however has not been uniformly accepted with studies, in primary endothelial cell cultures, showing that GC-induced repression of $\mathrm{NF \kappa B}$ is not related to elevations of IKB but rather to direct binding of the activated GC receptor to $\mathrm{NF \kappa B} .{ }^{37}$ The complication of the latter mechanism is that once GC-R complexes have been formed the complex is rapidly translocated to the nucleus whilst the protein-protein interaction, proposed between $\mathrm{NF \kappa B}$ and the GC-R complex presumably must be cytoplasmic. Studies in the adenocarcinoma A549 cell line suggest that in the absence of an inflammatory 
stimulus this classical translocation does take place, however in the presence of an inflammatory cytokine, such as tumour necrosis factor alpha (TNFa), GC-R complexes remain within the cytoplasm where they are then available for interaction with transcription factors. ${ }^{38}$ How this retention in the cytoplasm is brought about is unclear but the authors indicate that such a mechanism would allow cytoplasmic proteinprotein interaction.

Without doubt the modulation of NFkB by the GCs represents an important potential mechanism of antiinflammatory action. Interpretation of studies demonstrating GC-induced suppression of NFkB levels are complicated by the fact that, in the large part, the concentrations of GC used for these studies have been high $(0.1-1 \mu \mathrm{M})$. Whether these concentrations in vivo relate to those achieved during treatment ${ }^{39}$ is uncertain. Additionally other studies show that the non-steroidal anti-inflammatory drugs (NSAIDs) also have the capacity to effectively suppress NFKB levels. ${ }^{40}$ Since there is an enormous disparity between the effects of the GCs and the effects of the NSAIDs this suggests that mechanisms other than protein-protein interactions are also important in mediating the effects of the GCs at a molecular level.

\section{Inhibition of pro-inflammatory enzyme activity}

The inflammatory response in the skin involves several soluble mediators. The prostanoids and nitric oxide (NO) represent two important groups of inflammatory mediator ${ }^{41}$ that have attracted considerable attention as sites of anti-inflammatory action of the GCs. The pathways involved in the production of these two types of mediator are know $\mathrm{n}$ to be prone to inhibition by the GCs and it is now clear that decreased production of either of these class of mediators has a significant impact on many aspects of an inflammatory response. ${ }^{41} W_{1}$ th respect to the prostanoids the GCs suppress the induction of phospholipase $\mathrm{A}_{2}\left(\mathrm{PLA}_{2}\right)$ and cyclooxygenase-2 (COX2 ), both enzymes involved in the phospholipidarachidonate cascade (see Fig. 1). Importantly inhibition of $\mathrm{PLA}_{2}$ activity will not only suppress prostanoid levels but will also attenuate production of the leukotrienes and platelet-activating factor; other important mediators of inflammation. Similarly it is the synthesis of NO that is targeted by the GCs i.e. inhibition of $\mathrm{NO}$ synthase induction, an enzyme imperative for $\mathrm{NO}$ synthesis during inflammation. ${ }^{41}$ Overproduction of either prostanoids or $\mathrm{NO}$ is brought about by the induction of certain inducible enzymes that belong to the class of early response genes. Interestingly it seems that at a molecular level it is the early response genes which are particularly sensitive to GC action. These mechanisms of GC action will be discussed below with particular reference to their action in skin.
Extracellutar space

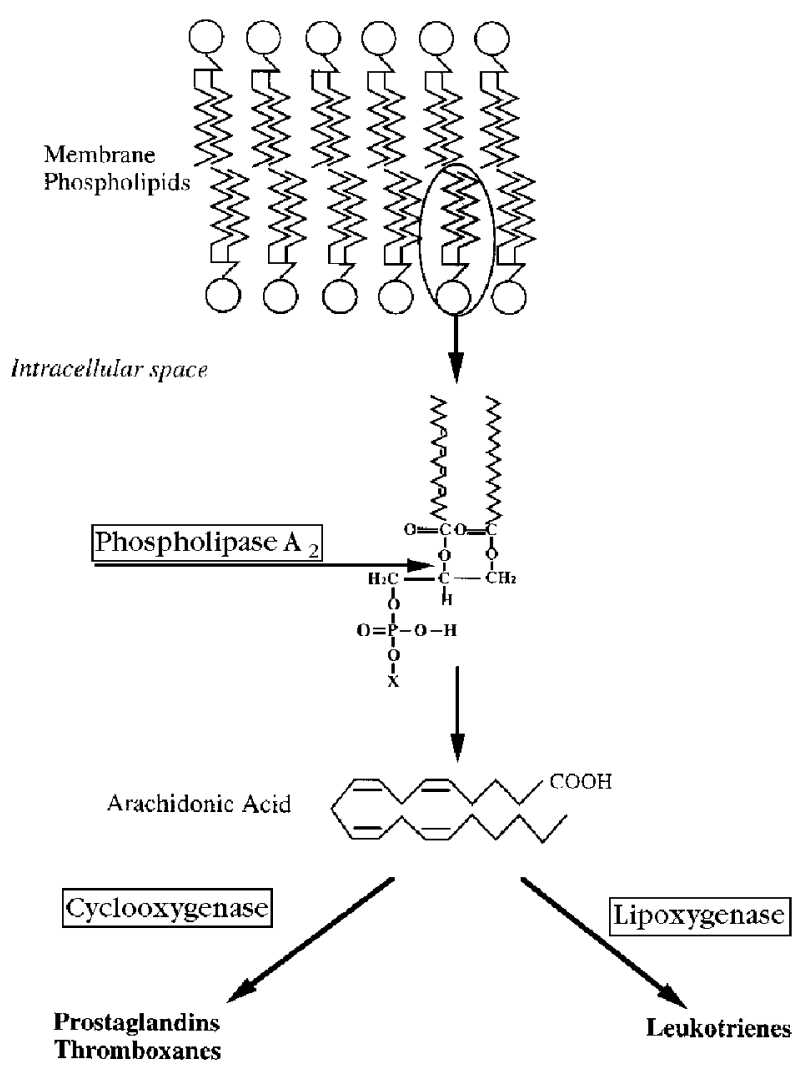

FIG. 1. The lipid mediator cascade.

\section{Phospholipase $A_{2}\left(P L A_{2}\right)$}

The first significant studies attempting to determine the site of antiinflammatory action of the GCs pinpointed the enzyme $\mathrm{PLA}_{2}$ as the most probable site. $\mathrm{PLA}_{2}$ activity results in conversion of membrane phospholipids into arachidonic acid and lysoPAF Arachidonic acid is the substrate for both COX-1 and COX-2 enzymes, the activities of which produce various prostanoids some of which possess inflammatory activity. It was in 1974 that the first report demonstrating that hydrocortisone reduced the output of prostaglandin (PG) E-like substances, in exercised dogs, was published. ${ }^{42}$ Soon after this initial observation it became clear that this decreased prostanoid production was a consequence of suppressed arachidonic acid release, implicating $\mathrm{PLA}_{2}$ as the site of GC action rather than direct inhibition of COX activity. ${ }^{43,44}$ This appears to be true for topical GCs in the skin since abnormally high levels of arachidonic acid, in psoriatic plaques, are reduced by topical GC treatment. ${ }^{45,46}$ Furthermore PLA $_{2}$ activity in psoriatic plaque samples is suppressed in those patients previously treated with topical $\mathrm{GC}^{47}$ It has even been proposed that measurement of $\mathrm{PLA}_{2}$ activity in psoriatics could efficiently form the basis of a model for the assessment of topical GC potency. In light of this evidence it was suggested that a 
reduction, by the GCs, of the elevated levels of PLA was primarily responsible for the benefits of this treatment in disease such as psoriasis and eczema. ${ }^{48}$ Whilst it is clear that GC treatment attenuates the abnormally high levels of arachidonate products in psoriatic skin it remains unclear as to what event comes first; decreases in the levels of these substances and consequently plaque resolution or plaque clearance followed by normalization of prostanoid levels.

The mechanism of GC-induced inhibition of $\mathrm{PLA}_{2}$ was first unravelled by the pharmacologists using classical bioassay techniques, in this case the guineapig perfused isolated lung preparation. The guinea-pig lung can be stimulated to release prostanoids by perfusion with either the substrate, arachidonic acid, or by other substances such as histamine or bradykinin. Using these techniques a series of elegant experiments demonstrated that the GC, dexamethasone, inhibited prostanoid release induced by the prostanoid-releasing substances but not by addition of the substrate, and most importantly that this process required de novo protein synthesis. ${ }^{49,50}$ Soon after these seminal experiments the protein responsible for this effect was identified by several independent groups simultaneously. In 1984 these groups came together and proposed a common nomenclature for the protein, lipocortin 1 (LC1). ${ }^{51}$ Since this time several different groups have demonstrated the antiinflammatory potential of this protein in pathological situations. Additionally the role of this protein as a physiological regulator was proposed in 1992 by Vishwanath et al. ${ }^{52}$ This group showed that the levels of both LC1 mRNA and protein were significantly decreased in adrenalectomized rats. From these findings this group proposed that LCl may be an important defence mechanism and decreases in the levels of this protein may predispose to enhanced inflammatory or immunological processes. In much the same way as the GCs the mechanism of action of LC1 was believed initially to be solely via inhibition of $\mathrm{PLA}_{2}$, however recent advances suggest that this inducible protein possesses multiple sites of action in inflammation which are both cellular and non-cellular (for review see Perretti ${ }^{53}$ ).

LC1 was thought to inhibit conversion of membrane phospholipids to arachidonic acid by a direct action on $\mathrm{PLA}_{2}$ and indeed there are recent studies with porcine splenic PLA Phich $_{2}$ concur with this proposition..$^{54}$ More recently however this theory has come under considerable scrutiny. In vitro studies using Escherichia coli cells or porcine pancreatic $\mathrm{PLA}_{2}$ show clearly that $\mathrm{LC} 1$ inhibits $\mathrm{PLA}_{2}$ activity, ${ }^{55}$ however this effect was not due to direct binding with the enzyme but rather by binding to the phospholipid substrate. This results in depletion of substrate availability and hence apparent decreased $\mathrm{PLA}_{2}$ activity. Studies measuring PLA ${ }_{2}$ activity in full thickness human skin homogenates agree with these findings showing that $\mathrm{LCl}$-induced inhibition of $\mathrm{PLA}_{2}$ activity is a function of substrate concentration and moreover, that $\mathrm{LCl}$ competes with $\mathrm{PLA}_{2}$ for phospholipid substrate. ${ }^{56}$ In contrast recent studies suggest that phosphorylation of $\mathrm{PLA}_{2}$ precedes and procures enzyme activation and further that this phosphorylation is sensitive to dexamethasone in a LC1-dependent manner. ${ }^{57}$ Finally the GCs may alter PLA 2 expression itself by an effect at the level of the gene which possesses a GRE (e.g. Schalkwijk et al. ${ }^{58}$ ). Whatever the mechanism of the induced decrease in conversion of membrane phospholipids into arachidonic acid the end-point remains the same i.e. resultant decrease in arachidonate products. Up till now there have been no direct studies either using epidermal cells in culture or in vivo to demonstrate directly that $\mathrm{LC1}$, or any other lipocortins, alter the levels of arachidonate products in the skin and are likewise associated with a resolution of the disease.

\section{(i) Lipocortin 1 in skin}

In 1989 Fava and co-workers were the first to identify basally expressed LCl in rat, porcine and human skin. ${ }^{59}$ The exact cellular location of this protein remains somewhat unclear with contradictory results from several different groups. Using antibodies generated by their group Fava showed, immunohistochemically, that LC1 could be found in discrete areas. The protein was situated predominantly in basal keratinocytes of the basement membrane. Staining for LC1 was also present in the epithelium of sweat glands in pig and human skin. Additionally, in human skin, there was an intense staining in the epithelial cells of hair follicles. However other studies have identified a different cellular localization for LC1 in the skin. For instance Kitajima's study in 1991 localized basal LC1 expression to the suprabasal layer of human skin, predominantly keratinocyte. ${ }^{60}$ It has been suggested that these differences between studies may reflect binding patterns of antibodies generated against different epitopes of the LC1 molecule and suggest that $\mathrm{LC1}$ may adopt different intercellular conformational states.

The intracellular location of LC1 is also controversial. Indeed it is now believed that there are multiple pools of LCl with only certain compartments conferring the biological activity of this protein. Figure 2 shows a schematic of the different pools of LC1 which have been identified. In the skin LC1 was found within the cytoplasm of epidermal cells in vitro, ${ }^{60}$ an observation supported more recently by studies in human skin biopsies, where LC1 was found in the cytoplasm of cells of the upper and middle epidermal layers. ${ }^{61}$ Of interest is the demonstration that in disease the intracellular localization of LC1 appears to change. In lesional psoriatic skin LC1 is found only in the cell membrane with no staining in 


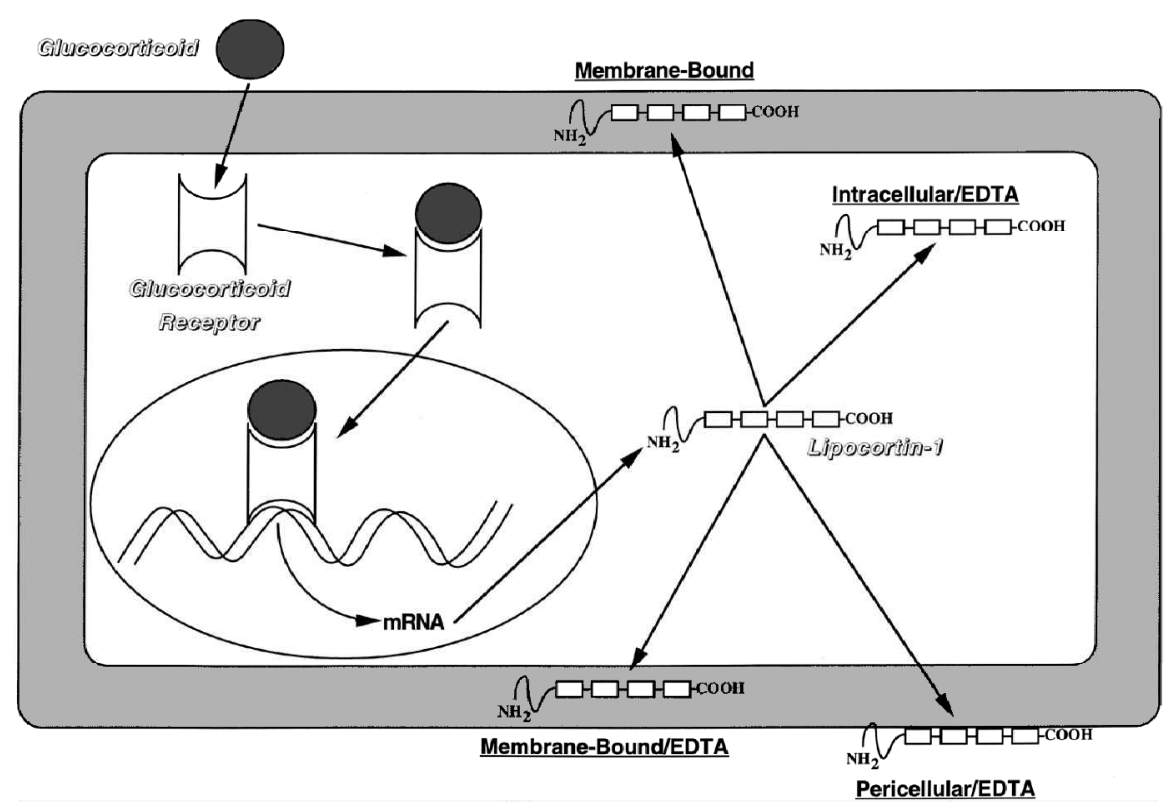

FIG. 2. Cellular distribution of distinct compartments of lipocortin 1.

the cytoplasm, demonstrating an apparent translocation of the protein. ${ }^{60,62}$ It is possible that the movement of $\mathrm{LCl}$ to the cell membrane is an active protective response of the cell in disease and, as suggested by the authors, may occur to allow the binding of $\mathrm{LCl}$ to phospholipids thereby decreasing inflammatory prostanoid production. However the movement of $\mathrm{LC1}$ was also associated with increases in the EGF receptor/tyrosine kinase, for which $\mathrm{LCl}$ is a substrate, and therefore it could be that the net availability of LC1 is in fact reduced. All of the studies mentioned so far have concentrated on the expression of basal LC1 in skin and its possible alteration in skin disease. We however addressed the concept that LC1 may be a mediator of the anti-inflammatory effects of topical GC therapy.

(ii) LCI expression in skin is GC-sensitive. Studies in rat have clearly demonstrated that topical GC treatment of the skin results in alterations in LC1 expression. Although measurement of the total LC1 content in skin homogenates showed no differences between GC-treated and vehicle-treated skin, examination of the pericellular compartment of LC1 using Western blotting, demonstrated that a pericellular pool of LC1 increases following topical GC treatment (betamethasone-17-valerate $0.018 \mathrm{mg} / \mathrm{cm}^{2}$ in acetone). ${ }^{63}$ Figure 2 shows schematic representation of the pools of LCl thought to exist in the cell. Recently it has been suggested that the pericellular compartment of $\mathrm{LCl}$ provides the biological activity of this protein. This proposal is supported by the fact that induced LC1 expression, in vivo, may be neutralized with antibody generated against this protein. ${ }^{64,65}$ Indeed pericellular LC1 expression, induced in rat skin, increased to a maximum at approximately $3 \mathrm{~h}$ following topical treatment returning to basal levels by $18 \mathrm{~h}$. This alteration of LC1 levels was also temporally associated with anti-inflammatory activity with approximately $50 \%$ inhibition of oedema produced in response to a range of putative mediators of inflammation. ${ }^{66}$ This change in LC1 levels was a specific effect of the GC since pretreatment of animals with the selective GC receptor antagonist, RU38486, prevented these differences. The situation in man is somewhat similar with an increase in LC1 expression in the pericellular compartment over a similar time course (A. Ahluwalia and R. J. Flower, unpublished observations). Unlike these studies others have found no increase in total LC1 levels following GC treatment of epidermal cells in vitro. ${ }^{67}$ This group showed that $16 \mathrm{~h}$ following treatment of cells with dexamethasone there was a significant decrease in the total expression of LC1 in both the cytosol and membrane of these cells. ${ }^{67}$ However these studies looked neither at shorter time points following treatment nor at the different compartments independently. If there had been an increase in the expression of the protein pericellularly it may be that this increase is achieved via the translocation of LC1 from either the intracellular or membranous compartments without necessarily a change in total $\mathrm{LC1}$ content. This of course in turn would result in a decrease in the $\mathrm{LCl}$ levels in the latter compartments which may explain the decreases in the protein seen in the epidermal cells at the $16 \mathrm{~h}$ timepoint. In A549 adenocarcinoma cells pericellular LC1 expression increased following dexamethasone treatment, reaching a maximum after $2 \mathrm{~h}^{64}$ Recently this same group have show $\mathrm{n}$, by measuring incorporation of labelled amino acid, that following GC treatment new protein 
synthesized by the cells was specifically directed to the cell surface in contrast with incorporation into the intracellular compartment in the absence of GC. $^{68}$

In a separate series of investigations the involvement of induced LC1 in procuring the effects of topical GC treatment in vivo have also been investigated. Our group have shown that the same topical GC regimen, as used in the above studies, resulted in an inhibition of the oedema produced in response to neurogenic stimulation; electrical stimulation of the saphenous nerve. Furthermore prior LCl immunoneutralization of rats, by systemic treatment with antibody, partially inhibited the anti-oedema effects of the GC. ${ }^{69}$ In another model of skin inflammation using intradermal administration of various putative mediators of inflammation, including platelet activating factor and 5-hydroxytryptamine, the inhibitory effects of topical GC treatment was also reversed by prior immunoneutralization with $\mathrm{LC1}$ antibody. ${ }^{66}$ These results together suggest that at least some of the anti-inflammatory effects of the topical GCs in the skin are brought about by the GC-inducible protein LC1.

The beneficial effects of the topical GCs in skin disease are not however restricted solely to their antiinflammatory properties. The anti-mitotic nature of these agents has been proposed to provide benefits in psoriasis where the cell turnover rate of the skin is considerably elevated above basal. Although there are now topical formulations believed to have little effect on cell turnover but retaining significant anti-inflammatory activity such as fluticasone. ${ }^{70}$ Studies in normal skin showed that topical GC treatment resulted in a significant decrease in epidermal mitoses in comparison with that in vehicle controls ${ }^{71}$ and similar findings have been shown in psoriatic skin. ${ }^{72}$ Dexamethasone has profound anti-proliferative effects on the A549 cell line and moreover these effects are associated with increases in LC1 and blocked by pretreatment of the cells with specific neutralizing antiserum to $\mathrm{LCl}^{64}$ Studies using the hairless mouse comparing the mitotic index and ${ }^{3} \mathrm{H}$-thymidine uptake in normal and GC-treated skin suggest that the effect of the GC may be a non-specific cell cycle effect or at the $\mathrm{G}_{1}$ interphase period. ${ }^{73} \mathrm{On}$ a more speculative note it would be interesting to determine whether the anti-mitotic effects of the topical GCs are brought about by LC1. This may then identify novel therapeutic opportunities for the treatment of psoriasis and importantly possibly identify the mechanism of skin thinning, a significant sideeffect of topical GC treatment.

\section{Cyclooxygenase (COX)}

Over the past decade there has been a growing body of evidence demonstrating that the GCs alter prostanoid synthesis by modulating the pathway at several levels. Studies in various cells types in vitro, including human dermal fibroblasts, have shown that the GC dexamethasone inhibits cytokine-stimulated COX synthesis. ${ }^{74}$ Whilst early studies demonstrated clearly that GCs had no effect on normal eicosanoid synthesis in either mice or man, other studies show that in situations where expression of COX has been upregulated, such as following treatment with pro-inflammatory substances including cytokines and lipopolysaccharide, prostanoid synthesis becomes sensitive to GC treatment. ${ }^{75}$ These differences whilst initially puzzling have been explained with the discovery that there are two isoforms of this enzyme; the constitutively expressed enzyme found in most cell types called COX-1, and an inducible form found in inflammatory cell types called COX-2. ${ }^{76}$ The COX-1 and COX-2 genes have now been cloned and show approximately $60 \%$ homology. ${ }^{77-79}$ It appears that whilst the induction of COX-2 is sensitive to GC treatment the expression of COX-1 is not (see Herschmann ${ }^{79}$ for review). Furthermore GC-induced decreases in COX-2 expression is due to a decrease in the stability of the mRNA rather than an effect on transcription per se. ${ }^{80,81}$

In vitro it is clear that it is the up-regulated prostanoid synthesis stimulated by COX-2 that is GCsensitive. In vivo animal studies, however have uncovered the fact that endogenous GCs are important regulators of basal prostanoid production since the lethal response to LPS in animals is more severe in adrenalectomized animals. ${ }^{82,83}$ Additionally adrenalectomy of mice results in substantial increases in COX expression and prostanoid production in peritoneal macrophages, that is associated with an increased lethality. ${ }^{84}$ Later studies showed that this enhanced COX expression was of the COX-2 isoform $^{85}$ suggesting that constitutive expression of COX-2 in murine peritoneal macrophages is tonically regulated by endogenous glucocorticoid.

Not all studies are consistent with the hypothesis that GCs downregulate COX activity and in some cases it seems that GC treatment has no effect or conversely elevates prostanoid production (for review see Duval and Freyss-Beguin ${ }^{86}$ ). In murine bone-marrow-derived mast cells dexamethsone selectively induces COX-1 expression with consequent elevation of PG formation. ${ }^{87}$ Whilst this potentiatory effect may at first appear contradictory on closer inspection this elevation may be advantageous to the organism since in certain situations $\mathrm{PGE}_{2}$, at least, is anti-inflammatory. In rat and murine skin in vivo, $\mathrm{PGE}_{2}$ inhibits oedema formation induced by inflammatory stimuli including platelet-activating factor and zymosan activated serum. ${ }^{88}$ The authors demonstrated that this inhibitory effect of the PGs is mediated by the prostanoid $\mathrm{EP}_{3}$ receptor. Support for these findings in man show that misoprostol, the selective $\mathrm{EP}_{3}$ receptor agonist, inhibits antigen- 
induced cutaneous late response in atopic patients. ${ }^{89}$ Inhibition of elevated prostanoid production and enhancement of, or even no effect upon, basal prostanoid production would provide an ideal approach for anti-inflammatory treatment with blockade of the damaging over-production of PGs and preservation of basal, potentially anti-inflammatory, PG production.

\section{Nitric oxide synthase (NOS)}

Nitric oxide (NO) plays an important role in several systems modelling physiological and pathological processes in the skin including; vasodilatation, inflammation, immunomodulation and oxidative damage to cells and tissues (for review see Lyons ${ }^{90}$ ). As such NO represents another important possible site of action of the GCs. NO is synthesized by a family of enzymes: the nitric oxide synthases of which there are three isoforms-the constitutive endothelial eNOS and neuronal $\mathrm{nNOS}$ (also collectively know $\mathrm{n}$ as $\mathrm{cNOS}$ ) and the inducible iNOS. GCs inhibit the induction of iNOS whilst leaving cNOS activity untouched. Studies in the early 1990s demonstrated that the GCs inhibited NO production only in situations where NO production was elevated by inflammatory substances such as LPS or cytokines, much in the same way as the COX system. The similarity between the two enzyme families extends further in that cNOS like COX-1, and in contrast to iNOS or COX-2, is resistant to modulation by GC treatment. ${ }^{90}$

NOS is expressed in skin and this has been demonstrated in animal ${ }^{91}$ and human skin. ${ }^{92}$ Indeed intradermal application of an NO synthase inhibitor causes decreases in local skin blood flow in animals ${ }^{93}$ and man. ${ }^{94}$ Thus it appears that NO is involved in basal dermal blood flow. Recent evidence shows significant increases in $\mathrm{NO}$ production in several dermal pathologies and it has been postulated that this elevated NO contributes to the aetiology of certain skin diseases. Studies using the NOS inhibitors suggest a role for $\mathrm{NO}$ in erythema and oedema formation in psoriasis and atopic dermatitis. ${ }^{94,95}$ Additionally iNOS is present in lesional psoriatic $\operatorname{skin}^{96,97}$ and specifically in involved sites in patients with atopic dermatitis and allergic contact dermatitis. ${ }^{96}$ It is clear that enhanced NO production, due to iNOS activity, may have a significant role to play in inflammatory skin conditions.

Thus it may be possible that resolution of inflammatory skin conditions with the GCs may be due, at least in part, to the inhibition of iNOS induction in the skin. There have been no studies, as of yet, which have clearly demonstrated that following topical GC treatment there is a consequent reduction of iNOS activity in sites subjected to an inflammatory stimulus such as LPS or carrageenin or indeed in human skin biopsies.

\section{Modulation of mast cell activity}

An alternative mechanism for the anti-inflammatory action of GCs has been proposed to be the modulation of mast cell numbers and activity. Degranulation of mast cells with consequent release of histamine plays a major role in hypersensitivity responses as well as contributing to other types of inflammatory skin diseased states. Mast cells possess high affinity $\mathrm{IgE}$ receptors and in atopic individuals exposure to antigen results in degranulation since the antigen binds to the $\operatorname{IgE}$ attached to the receptor. The mast cell contains several pro-inflammatory mediators and degranulation will consequently release these proinflammatory substances, such as histamine and PGs, into the local environment. ${ }^{98}$ Therefore inhibition of this mast cell component should have significant antiinflammatory effects. Topical GC treatment causes a decrease in mast cell numbers in the skin $^{99}$ and this decrease in numbers is responsible for the decrease in histamine content of the treated skin. Despite initial studies with human skin in vitro showing that GC treatment, for only $2 \mathrm{~h}$, attenuates histamine release in response to allergen challenge ${ }^{100}$ early studies in the airways, in vivo, suggested that the GCs had no effect on histamine release in an allergic reaction. However it has become clear that duration of treatment with GC is an important determinant of the efficacy of these agents in the skin. ${ }^{100}$ Indeed a 1-2 week treatment with topical GC causes complete block of the allergen-induced late response and attenuates the immediate wheal and flare response in the skin of the human forearm. ${ }^{101,102}$ Recent studies also show GCinduced reduction of IgE receptor-mediated expression of pro-inflammatory cytokine in murine bone marrow derived mast cells. ${ }^{103}$

\section{Inhibition of cytokine activity}

It is clear that the expression and activity of several important inflammatory cytokines may be suppressed by prior treatment with glucocorticoids. Suppression of cytokines expression, in general, appears not to be due to interaction of the GC-R complex with GREs, since most cytokine genes do not possess a GRE element. The only clear exception to this is the IL-6 gene ${ }^{104,105}$ although there is some evidence for the presence of a GRE on the IL-8 gene of a human fibrosarcoma cell line ${ }^{106}$ and more recently a negative regulatory region containing a negative GRE has been identified in the human IL-1 $\beta$ gene. ${ }^{107}$ Reports suggest that the transcription of several cytokines is lowered by the GCs following inactivation of specific transcription factors, such as AP-1 and NFKB, as described earlier. This mode of action has been suggested to be responsible for the attenuated production of IL-6, IL-8 and IL-2. ${ }^{105,108,109}$ Finally the third mechanism for GC-induced inhibition of cyto- 
kine expression is through the enhancement of mRNA instability, i.e. a shortened half-life, for certain cytokines (for e.g. see Lee et al. ${ }^{110}$ ). As mentioned the GCs also inhibit the activity of many cytokines and there is a vast literature documenting these actions and this review will not discuss these further. Of particular interest however have been the demonstrations that the GC-sensitive actions of the cytokines in models of cellular migration, specifically IL-1 $\beta$ and IL8 , are mediated partially by $\mathrm{LC} 1{ }^{111}$ Additionally in psoriatic skin both IL-1 and IL-6 are significantly elevated $\mathrm{d}^{112,113}$ and both of these studies postulate that these cytokines may be implicated with the pathology of the disease.

\section{Summary}

The topical GCs still remain one of the most effective and popular forms of treatment of various inflammatory skin disease states. These agents are clearly a complex class of drugs that modulate the activity of several pivotal processes and mediators of inflammation. Modulation of the levels and/or compartmentalization of the GC-inducible, anti-inflammatory, antiproliferative protein, LC1, following topical GC treatment provides solid evidence supporting the suggestion that this protein plays an important role in the action of topical GCs. Exploration of the possibilities of more specific treatment of skin disease with $\mathrm{LC1}$ related products may provide novel more efficient modalities for treatment of inflammatory skin disease.

\section{References}

1. Hench PS, Kendall EC, Slocumb CH, Polley HF. The effect of the adrenal cortex (17-hydroxy-11-de-hydrocortisone: compund E) and of pituitary adrenocorticotropic hormone on rheumatoid arthritis; preliminary report. Proc Staff Meet Mayo Clin 1949; 24: 181-197.

2. Spies TD, Stone RE. Effect of local application of synthetic cortisone acetate on lesions of iritis and uveitis, of allergic dermatitis, and psoriasis. South Med J Oct 1950; 43: 871-874.

3. Newman BA, Feldman FF. Effects of topical cortisone on chronic discoid lupus erythematosus and necrobiosis lipoidica diabeticorum. J Invest Dermatol 1951; 17: 3-6.

4. Sulzberger MB, Witten VH. The effect of topically applied compound $\mathrm{F}$ in selected dermatoses. I Invest Dermatol 1952; 19: 101-102.

5. Fisher LB, Maibach HI. The effect of corticosteroids on human epidermal mitotic activity. Arch Derm 1971; 103: 39-44.

6. Van De Kerkhof PC, Van Erp PE. The role of epidermal proliferation in the pathogenesis of psoriasis. Skin Pharmacol 1996; 9: 343-354.

7. Walker BR, Williams BC. Corticosteroids and vascular tone: mapping the messenger maze. Clin Sci 1992; 82: 597-605.

8. Noon JP, Evans CE, Haynes WG, Webb DJ, Walker BR. A comparison of techniques to assess skin blanching following the topical application of glucocorticoids. $\mathrm{Br}$ J Dermatol 1996; 134: 837-842.

9. McKenzie AW, Stoughton RD. Method for comparing percutaneous absorption of steroids. Arch Dermatol 1962; 86: 608-610.

10. Vickers CHF. Existence of a reservoir in the stratum corneum. Arch Dermatol 1963; 88: 72-75.

11. Baker JRJ, Christian RA, Simpson P, White AM The binding of topically applied glucocorticoids to rat skin. Br J Dermatol 1977; 96: 171-178.

12. Epstein EH, Munderloh NH Glucocorticoid receptors of mouse epidermis and dermis. Endocrinol 1971; 108: 703-711.

13. Epstein EH, Bonifas JM. Glucocorticoid receptors of normal human epidermis. J Invest Dermatol 1982; 78: 144-146.

14. Ponec M, Kempenaar JA, De Kloet ER Corticoids and cultured human epidermal keratinocytes: specific intracellular binding and clinical efficacy. I Invest Dermatol 1981; 76: 211-214.
15. Serres M, Viac J, Schmitt D. Glucocorticoid receptor localization in human epidermal cells. Arch Dermatol Res 1996; 288: 140-146.

16. Gorski J, Toft D, Shyamala G, Smith D, Notides A. Hormone receptor studies on the interaction of estrogen with the uterus. Recent Prog Hormone Res 1968; 24: 45-80.

17. Gorski J, Malayer R, Gregg DW, Lundeen SG. Just where are the steroid receptors anyway? Endocrine J 1994; 2: 99-100.

18. Rupprecht R, Reul JM, van-Steensel B, Spengler D, Soder M, Berning B, Holsboer F, Damm K. Pharmacological and functional characterization of human mineralocorticoid and glucocorticoid receptor ligands. Eur J Pharmacol 1993; 247: 145-154.

19. Gasc JM, Delahaye F, Baulieu EE. Compared intracellular localisation of the glucocorticosteroid and progesterone receptors: an immunocytochemical study. Exp Cell Res 1989; 181: 492-504.

20. Brink M, Humbel BM, De Kloet R, Van Driel R. The unliganded glucocorticoid receptor is localized in the nucleus, not in the cytoplasm. Endocrinology 1992; 130: 3575-3581.

21. Akner G, Wikstrom AC, Gustafsson JA. Subcellular distribution of the glucocorticoid receptor and evidence for its association with microtubules. J Steroid Biochem Mol Biol 1995; 52: 1-16.

22. Szapary D, Barber T, Dwyer NK, Blanchette-Mackie EJ, Simons SS Microtubules are not required for glucocorticoid receptor mediated gene induction. J Steroid Biochem Mol Biol 1994; 51: 143-148.

23. Marks R, Barlow JW, Funder JW. Steroid-induced vasoconstriction: glucocorticoid antagonist studies. J Clin Endocrinol Metab 1982; 54: 1075-1077.

24. Gaillard RC, Poffet D, Riondel AM, Saurat J-H. RU 486 inhibits peripheral effects of glucocorticoids in humans. J Clin Endocrinol Metab 1985; 61: 1009-1011.

25. Pratt WB. The role of heat shock proteins in regulating the function, folding and trafficking of the glucocorticoid receptor. $J$ Biol Chem 1993; 268: 21455-21458.

26. Smith DE, Toft DO. Steroid receptors and their associated proteins. Mol Endocrinol 1993; 7: 4-11.

27. Brann DW, Hendry LB, Mahesh VB. Emerging diversities in the mechanism of action of steroid hormones. J Steroid Biochem Mol Biol 1995; 52: 113-133.

28. Picard D, Saber SJ, Yamamoto KR. A movable and regulable inactivation function within the steroid binding domain of the glucocorticoid receptor. Cell 1988; 54: 1073-1080.

29. Sanchez ER, Toft DO, Sclesinger MJ, Pratt WB. Relationship of the $90 \mathrm{kDa}$ phosphoprotein associated with the untransformed and transformed states of the L-cell glucocorticoid receptor. J Biol Chem 1987; 262: 6986-6991.

30. Raynal P, Pollard HB. Annexins: the problem of assessing the biological role for a gene family of multifunctional calcium- and phospholipid-binding proteins. Biochim Biophys Acta 1994; 1197: 63-93.

31. Whitmarsh AJ, Davis RJ. Transcription factor AP-1 regulation by mitogen-activated protein kinase signal transduction pathways. J Mol Med 1996; 74: 589-607.

32. Baldw in AS. The NFkB and IkB proteins-new discoveries and insights. Ann Rev Immunol 1996; 14: 649-681.

33. Jonat C, Rahmsdorf HI, Park HI, Cato ACB, Gebel S, Ponta H, Herrlich P. Antitumor promotion and antiinflammation:downregulation of AP-1 (Fos/Jun) activity by glucocorticoid hormone. Cell 1990; 62 1189-1204.

34. Baeuerle PA, Baltimore D. IкB- a specific inhibitor of the NFKB transcription factor. Science 1988; 242: 540-546.

35. Scheinman RI, Cogswell PC, Lofquist AK, Baldwin AS. Role of transcriptional activation of $\mathrm{IkB}$ in mediation of immunosuppression by glucocorticoids. Science 1995; 270: 283-286.

36. Auphan N, DiDonato JA, Rosette C, Helmberg A, Karin M. Immunosuppression by glucocorticoids: inhibition of NFkB activity through induction of IkB synthesis. Science 1995; 270: 286-290.

37. Brostjan C, Anrather J, Csizmadia V, Stroka D, Soares M, Bach FH, Winkler $\mathrm{H}$. Glucocorticoid-mediated repression of NFkB activity in endothelial cells does not involve induction of $\mathrm{IkB}$ synthesis. $J$ Biol Chem 1996; 271: 19612-19616.

38. Adcock IM, Brown CR, Barnes PJ. Tumour necrosis factor alpha causes retention of activated glucocorticoid receptor within the cytoplasm of A549 cells. Biochem Biophys Res Commun 1996; 225: 545-550.

39. Boumpas DT. A novel action of glucocorticoids-NF+B inhibition. $\mathrm{Br} J$ Rheumatol 1996; 35: 711-718.

40. Weber C, Wolfgang E, Pietsch A, Weber PC. Aspirin inhibits nuclear factor $\mathrm{kB}$ mobilization and monocyte adhesion in stimulated human endothelial cells. Circulation 1995; 91: 1914-1917.

41. Appleton I, Tomlinson A, Willoughby DA. Induction of cyclo-oxygenase and nitric oxide synthase in inflammation. Adv Pharmacol 1996; 35: 27-79.

42. Herbaczynski-Cedro K, Staszewska-Barcyak J. Adrenocortical hormones and the release of prostaglandin-like substances (PLS). Abstracts of the Hungarian Pharmacological Society, Budapest 1974; 19 (abstract).

43. Blackwell GJ, Flower RJ, Nijkamp FP, Vane JR. Phospholipase $\mathrm{A}_{2}$ activity of guinea-pig isolated perfused lungs: stimulation and inhibition by antiinflammatory steroids. $\mathrm{Br} J$ Pharmacol 1978; 62: 79-89. 
44. Hong SCL, Levine L Inhibition of arachidonic acid release from cells as the biochemical action of anti-inflammatory corticosteroids. Proc Natl Acad Sci USA 1976; 73: 1730-1734.

45. Hammarstrom S, Hamberg M, Duell EA, Satwiski MA, Anderson TF Voorhees JJ. Glucocorticoid in inflammatory proliferative skin disease reduces arachidonic and hydroxyeicosatetraenoic acids. Science 1977; 192: 994-996.

46. Voorhees JJ, Duell EA, Anderson TF, Stawiski MA, Hammarstrom S, Hamberg M Pharmacological effects of glucocorticoid on arachidonic acid content of lesions of psoriasis. Adv Prost Thromb Res 1978; 3: $175-181$.

47. Norris JFB, Ilderton E, Yardley HJ, Summerly R, Forster S. Utilization of epidermal phospholipase $\mathrm{A}_{2}$ inhibition to monitor topical steroid action. Br J Dermatol 1984; 27: 195-203.

48. Forster S, Ilderton E, Norris JFB, Summerly R, Yardley HJ. Characterisation and activity of phopsholipase $A_{2}$ in normal human epidermis and in lesion-free epidermis of patients with psoriasis and eczema. $\mathrm{Br}$ J Dermatol 1985; 112: 135-147.

49. Flower RJ, Blackwell GJ. Anti-inflammatory steroids induce biosynthesis of a phospholipase $\mathrm{A}_{2}$ inhibitor which prevents prostaglandin generation. Nature 1979; 278: 456-459.

50. Danon A, Assouline G. Inhibition of prostaglandin biosynthesis by corticosteroids requires RNA and protein synthesis. Nature 1978; 273: 552-554.

51. Di Rosa M, Flower RJ, Hirata F, Parente L, Russo-Marie F. Lipocortins a nomenclature announcement. Prostaglandins 1984; 28: 441-444.

52. Vishwanath BS, Frey FJ, Bradbury M, Dallman MF, Frey BM. Adrenalectomy decreases lipocortin-1 messenger ribonucleic acid and tissue protein content in rats. Endocrinology 1992; 130: 585-591.

53. Perretti M. Lipocortin-derived peptides. Biochem Pharmacol 1994; 47: 931-938.

54. Kim KM, Kim DK, Park YM, Kim CK, Na DS. Annexin-1 inhibits phopholipase A2 by specific interaction, not by substrate depletion. FEBs Lett 1994; 343: 251-255.

55. Davidson FF, Dennis EA, Powell M, Glenney JR. Inhibition of phopholipase $\mathrm{A}_{2}$ by 'lipocortins' and calpactins. J Biol Chem 1987; 262: 1698-1705.

56. Bastian BC, Sellert C, Seekamp A, Romisch J, Paques E-P, Brocker E-B. Inhibition of human skin phopholipase $\mathrm{A}_{2}$ by 'lipocortins' is an indirect effect of substrate/lipocortin interaction. J Invest Dermatol 1993; 101: 359-363.

57. Croxtall JD, Newman SP, Choudhury Q, Flower RJ. The concerted regulation $\mathrm{cPLA}_{2}, \mathrm{COX} 2$ and lipocortin 1 expression by IL-1b in A549 cells. Biochem Biophys Res Commun 1996; 220: 491-495.

58. Schalkwijk C, Vervoordeldonk M, Pfeilschifter J, van den Bosch H Interleukin $1 \beta$-induced cytosolic phospholipase $\mathrm{A}_{2}$ activity and prote in synthesis is blocked by dexamethasone in rat mesangial cells. FEBS Lett 1993; 33: 339-343.

59. Fava RA, McKanna J, Cohen S. Lipocortin 1 (p35) is abundant in a restricted number of differenetiated cell types in adult organs. J Cell Physiol 1989; 141: 284-293.

60. Kitajima Y, Owada K, Mitsui H, Yaoita H Lipocortin 1 (annexin 1) is preferentially localized on the plasma membrane in keratinocytes of psoriatic lesional epidermis as shown by immunofluorescence microscopy. J Invest Dermatol 1991; 97: 1032-1038.

61. Ikai K, Shimizu K, Ando Y, Furukawa F, Imamura S, Kannagi R. Immunohistochemical localization of lipocortins in normal and psoriatic skin. Arch Dermatol Res 1993; 285: 296-299.

62. Serres M, Viac J, Comera C, Schmitt D. Expression of annexin 1 in freshly isolated human epidermal cells and in cultured keratinocytes. Arch Dermatol Res 1994; 286: 268-272.

63. Ahluwalia A, Mohamed RW, Flower RJ. Induction of lipocortin 1 by topical steroid in rat skin. Biochem Pharmcol 1994; 48: 1647-1654.

64. Croxtall JD, Flower RJ. Lipocortin 1 mediates dexamethasone-induced grow th arrest of the A549 lung adenocarcinoma cell line. Proc Natl Acad Sci 1992; 89: 3571-3575.

65. Browning JL, Ward MP, Wallner BP, Pepinsky RB. Studies on the structural properties of lipocortin-1 and the synthesis by steroids. In: Meli M, Parent L, eds. Cytokines and Lipocortins in Inflammation and Differentiation. Chichester: Wiley-Leiss, 1990; 27-45.

66. Ahluwalia A, Mohammed RW, Flower RJ. Glucocorticoid-induced lipocortin 1 in rat skin is associated with anti-inflammatory activity. Can J Physiol Pharmacol 1994; 72: 10.1.34-10.1.30 (abstract).

67. Serres M, Comera C, Schmitt D. Annexin 1 regulation in human epidermal cells. Cell Mol Biol 1994; 40: 710-706.

68. Croxtall JD, Flower RJ. Antisense oligonucleotides to human lipocortin 1 inhibit glucocorticoid-induced inhibition of A549 cell growth and eicosanoid synthesis. Biochem Pharmacol 1997; 48: 1729-1739.

69. Ahluwalia A, Newbold P, Brain SD, Flower RJ. Topical glucocorticoids inhibit neurogenic inflammation: involvement of lipocortin 1. Eur J Pharmacol 1995; 283: 193-198.

70. Chu AC, Munn S. Fluticasone propionate in the treatment of inflammatory dermatoses. Br J Clin Pract 1995; 49: 131-133.

71. Fischer LB, Maibach HI. The effect of corticosteroids on human epidermal mitotic activity. Arch Dermatol 1971; 103: 39-44.
72. Baxter DL, Stoughton RB. Mitotic index of psoriatic lesions treated with anthralin, glucocorticosteroid and occlusion only. J Invest Dermatol 1970; 54: 410-412.

73. Marks R, Williams K. The action of topical corticosteroids on the epidermal cell cycle. In: Wilson L, Marks R, eds. Mechanisms of Topical Corticosteroid Activity. Edinburgh: Churchill Livingstone, 1976; 39-74.

74. Raz A, Wyche A, Needleman P. Temporal and pharmacological division of fibroblast cyclooxygenase expression into transcriptional and translational phases. Proc Natl Acad Sci 1989; 86: 1657-1661.

75. Masferrer JL, Zweifel BS, Seibert K, Needleman P. Selective regulation of cellular cyclooxygenase by dexamethasone and endotoxin in mice. $J$ Clin Invest 1990; 866: 1375-1379.

76. Han JW, Sadowski H, Young DA, Macara IG. Persistent induction of cyclooxygenase in $\mathrm{p} 60^{\mathrm{v}-\mathrm{rc}}$ transformed 3T3 fibroblasts. Proc Natl Acad Sci 1990; 87: 3373-3377.

77. DeWitt DL Prostaglandin endoperoxide synthase - regulation of enzyme expression. Biochim Biophys Acta 1991; 1083: 121-134.

78. Hla T, Ristimaki A, Appleby S, Barriocanal JG. Cyclooxygenase gene expression in inflammation and angiogenesis. Ann NY Acad Sci 1993; 696: 197-204.

79. Herschmann HR. Regulation of prostaglandin synthase-1 and prostaglandin synthase-2. Cancer Metastasis Reviews 1994; 13: 241-256.

80. Kujubu DA, Herschman HR Dexamethasone inhibits mitogen induction of the T1S10 prostaglandin synthase/cyclooxygenase gene. J Biol Chem 1992; 267: 7991-7994.

81. Ristimaki A, Narko K, Hla T. Down-regulation of cytokine-induced cyclooxygenase-2 transcript isoforms by dexamethasone: evidence for posttranscriptional regulation. Biochem J 1996; 318: 325-331.

82. Bertini R, Bianchi M, Ghezzi P. Adrenalectomy sensitizes mice to the lethal effects of Interleukin-1 and tumor necrosis factor. J Exp Med 1988; 167: 1708-1712.

83. Flower RJ, Parente L, Persico P, Salmon JA. A comparison of the acute inflammatory response in adrenalectomized and sham-operated rats. $B r$ J Pharmacol 1986; 87: 57-62.

84. Masferrer JL, Seibert K, Zweifel BS, Needleman P. Endogenous glucocorticoids regulate an inducible cyclooxygenase enzyme. Proc Natl Acad Sci 1992; 89: 3917-3921.

85. Masferrer JL, Srinivasa T, Zweifel BS, Seibert P, Gilbert RS, Herschman $H R$. In vivo glucocorticoids regulate cyclooxygenase-2 but not cyclooxygenase-1 in peritonal macrophages. J Pharmacol Exp Therap 1994; 270 : $1340-1344$

86. Duval D, Freyss-Beguin M. Glucocorticoids and prostaglandin synthesis: we cannot see the wood for the trees. Prostaglandins Leukotrienes and Essential Fatty Acids 1992; 45: 85-112.

87. Samet JM, Fasano MB, Fonteh AF, Chilton FH. Selective induction of prostaglandin $\mathrm{G} / \mathrm{H}$ synthase I by stem cell factor and dexame thasone in mast cells. J Biol Chem 1995; 270: 8044-8049.

88. Ahluwalia A, Perretti M. Anti-inflammatory effect of prostanoids in mouse and rat skin: evidence for a role of $\mathrm{EP}_{3}$ receptors. J Pharmaco Exp Therap 1994; 268: 1526-1531.

89. Alam R, Dejarnatt A, Stafford S, Forsythe PA, Kumar D, Grant JA Selective inhibition of the cutaneous late but not immediate allergic response to antigens by misoprostol, a PGE analog. Am Rev Respir Dis 1993; 148: 1066-1070.

90. Lyons CR. The role of nitric oxide in inflammation. Adv Im munol1995; 60: 323-371.

91. Dippel E, Schonfelder D, Czarnetzki BM. Localisation and activity of nitric oxide synthase during the murine hair growth cycle. I Invest Dermatol 1993; 101: 403-400.

92. Goldsmith PC, Levell NJ, Foreman JC, Polak JM, Dowd PM Nitric oxide synthase: immunolocalisation and function in human skin. I Invest Dermatol 1993; 101: 419-410.

93. Lawrence E, Brain SD. Responses to endothelins in the rat cutaneous microvasculature: a modulatory role of locally produced nitric oxide. Br J Pharmacol 1992; 106: 733-738.

94. Goldsmith PC, Leslie TA, Hayes NA, Levell NJ, Dowd PM, Foreman JC. Inhibitors of nitric oxide synthase in human skin. J Invest Dermatol 1996; 106: 113-118.

95. Warren JB. Nitric oxide and human skin blood flow responses to acetylcholine and ultraviolet light. Faseb J 1994; 8: 247-251.

96. Rowe A, Farrell AM, Bunker CB. Constitutive endothelial and inducible nitric ox ide synthase in inflammatory dermatoses. Br J Dermato l 1997; 136: $18-23$.

97. Kolb-Bachofen V, Fehsel K, Michel G, Ruzicka T. Epidermal keratinocyte expression of inducible nitric oxide synthase in skin lesions of psoriasis vulgaris. Lancet 1994; 344: 139-130.

98. Galli SJ. New concepts about the mast cell. New Engl J Med 1993; 328 $257-265$.

99. Lavker RM, Schechter NM. Gutaneous mast cell depletion results from topical corticosteroid usage. J Imm unol 1985; 135: 2368-2373.

100. Greaves MW, Plummer VM. Glucocorticoid-inhibition of antigen-evoked histamine release from human skin. Immunology 1974; 27: 359-364

101. Andersson M, Pipkorn U. Inhibition of the dermal immediate allergic reaction through prolonged treatment with topical glucocorticosteroids. J Allergy Clin Immunol 1987; 79: 345-349. 
102. Pipkorn U, Hammarlund A, Enerback L Prolonged treatment with topical glucocorticoids results in an inhibition of the allergen-induced weal-and-flare response and recuction in skin mast cell numbers and histamine content. Clin Exp Allergy 1989; 19: 19-25.

103. Eklund KK, Humphries DE, Xia Z, Ghilyal N, Friend DS, Gross V, Stevens RL. Glucocorticoids inhibit the cytokine-induced proliferation of mast cells, the high affinity $\operatorname{IgE}$ receptor-mediated expression of TNFa, and the IL-10-induced expression of chymases. J Immunol 1997; 158: 4373-4380.

104. Ray A, LaForge KS, Sehgal PB. On the mechanism of efficient repression of the IL- 6 promotor by glucocorticoids: enhancer TATA box and RNS start site occlusion. Mol Cell Biol 1990; 10: 5736-5746.

105. Ray A, Zhang D-H, Siegel MD, Ray P. Regulation of interleukin-6 gene expression by steroids. Ann NY Acad Sci 1995; 762: 79-87.

106. Mukaida N, Gussella GL, Kasahara T, Ko Y, Zachariae CO, Kawai T, Matsushima K. Molecular analysis of the inhibition of interleukin-8 production by dexamethasone in a human fibrosarcoma cell line. Immunology 1992; 75: 674-679.

107. Zhang G, Zhang L, Duff GW. A negative regulatory region containing a glucocorticosteroid response element (nGRE) in the human interleukin-1beta gene. DNA Cell Biol 1997; 16: 145-152.

108. Pagliogianni F, Raptis A, Ahuja SS, Najjar SM, Boumpas DT. Negative transcriptional regulation of human II-2 gene by glucocorticoids through interference with nuclear transcription factors AP-1 and NF-AT. J Clin Invest 1993; 91: 1481-1489.

109. Mukaida N, Morita M, Ishikawa Y, Rice N, Okamoto S, Kasahara T, Matsushima K. Novel mechanism of glucocorticoid-mediated interleukin 8 gene repression. J Biol Chem 1994; 269: 13289-13295.

110. Lee SW, Tsou A-P, Chan H, Thomas J, Petrie K, Eugui EM, Allison AC. Glucocorticoids selectively inhibit the transcription of the interleukin $1 \mathrm{~b}$ gene and decrease the stability of interleukin $1 \mathrm{~b}$ mRNA. Proc Natl Acad Sci 1988; 85: 1204-1208.

111. Perretti M, Flower RJ: Cytokines, glucocorticoids and lipocortins in the control of neutrophil migration. Pharmacol Res 1994; 30: 53-59.

112. Grossman RM, Krueger J, Yourish D, Granelli-Piperno A, Murphy DP, May LT, Kupper TS, Sehgal PB, Gottlieb AB. Interleukin 6 is expressed in high levels in psoriatic skin and stimulates proliferation of cultured human keratinocytes. Proc Natl Acad Sci 1989; 86: 6367-6371.

113. Camp RDR, Fincham NJ, Cunningham FM, Greaves MW, Morris J, Chu A. Psoriatic skin lesions contain biologically active amounts of and interleukin 1-like compound. J Immunol 1986; 137: 3469-3474.

ACKNOWLEDGEMENTS. I would like to thank the British Heart Foundation for their support and Professor R. J. Flower and Dr Mauro Perretti for their helpful discussions. I would also like to thank Dr Adrian Hobbs for his kind help in preparation of this manuscript. 


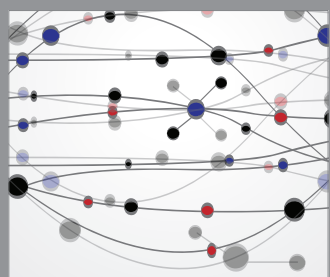

The Scientific World Journal
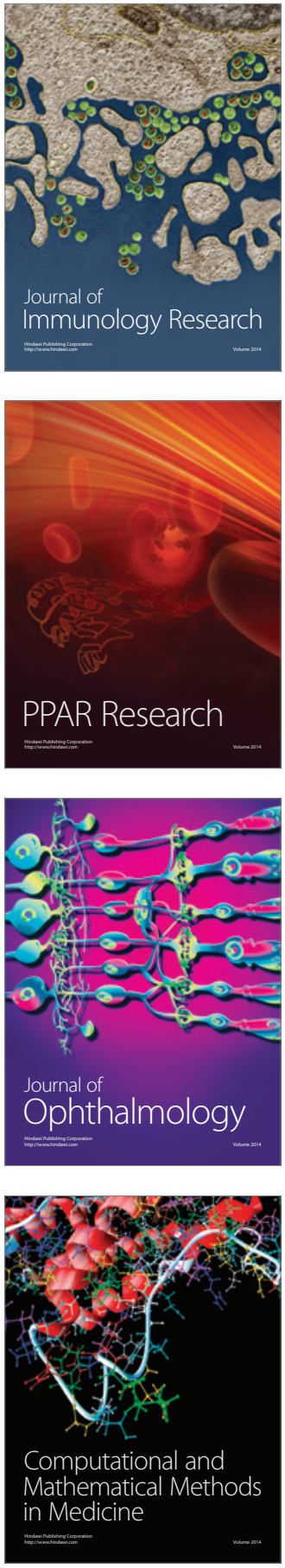

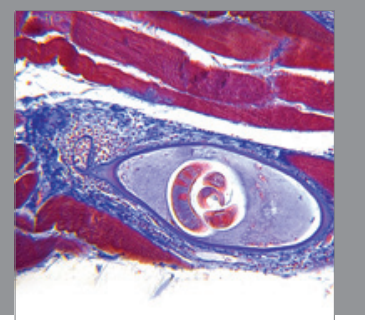

Gastroenterology

Research and Practice
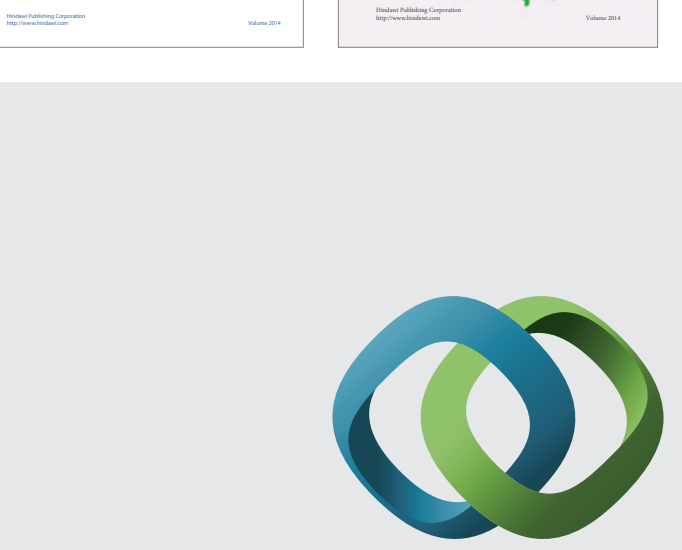

\section{Hindawi}

Submit your manuscripts at

http://www.hindawi.com
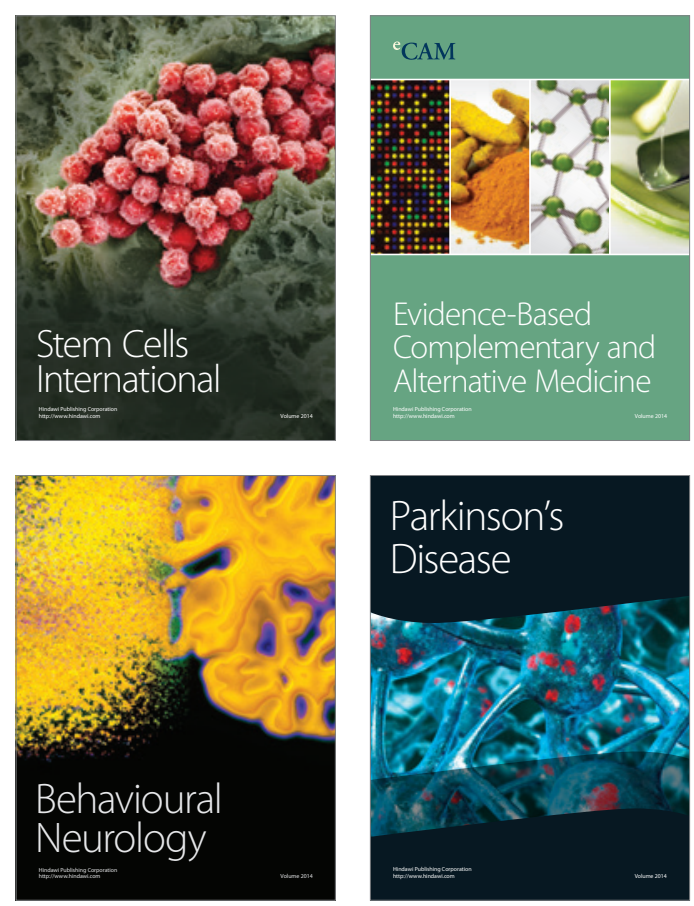

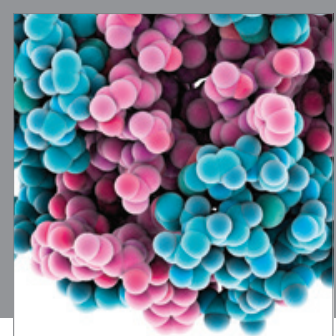

Journal of
Diabetes Research

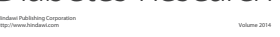

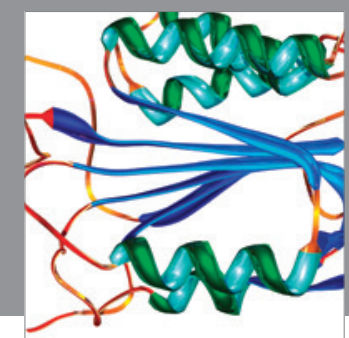

Disease Markers
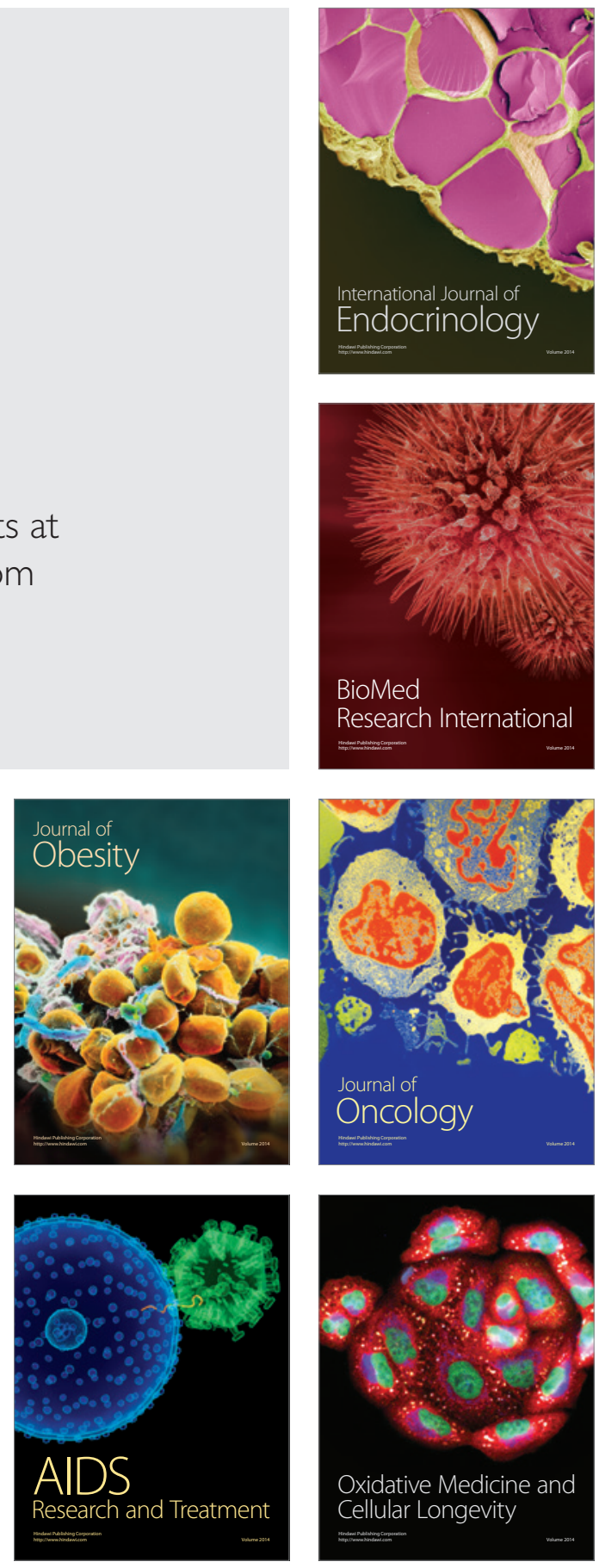